\title{
Risk assessment methods for life cycle costing in buildings
}

\author{
Olufolahan Oduyemi ${ }^{1,}$, Michael Okoroh ${ }^{2}$, and Oluwaseun Samuel Fajana ${ }^{3}$ \\ ${ }^{1}$ College of Engineering and Technology, University of Derby, UK \\ 2 Al Imam Mohammad Ibn Saud Islamic University, Riyadh, Saudi Arabia \\ 3 School of Arts Design and the Built Environment, Nottingham Trent University, UK
}

Received: 16 July 2016 / Accepted: 19 September 2016

\begin{abstract}
Purpose. There has been a growing consciousness of the significance of considering the costs of buildings and of developing financial methods to evaluate the life cycle costs (LCC) of buildings in use. Before any decision to invest capital in a building project or existing infrastructure is taken, it is essential that all corporate occupants and stakeholders in the policymaking practice are fully aware of the risks that are inherent as any LCC estimate will always involve a degree of risk exposure.

Design/methodology/approach. Questionnaire survey to 120 construction professionals was used to gauge the current level of awareness, usage and advocated benefits of risk assessment methods in LCC. The questionnaire comprised three main sections each exploring different parts of the research question.

Findings. The key findings of the statistical analysis indicated that there is a low awareness and usage of risk assessment methods and four factors were the most advocated benefits of its application to corporate occupiers and decision makers. This study fills the gap in the existing knowledge by addressing concerns over risk assessment to improve the confidence in LCC.

Research limitations/implications. Although the data used in this paper was from professionally qualified members of either the Royal Institution of Chartered Surveyors (RICS), the Chartered Institute of Building (CIOB) and the British Institute for Facilities Management (BIFM), the research is limited in some ways in that it does not cover all the professionals in the construction industry. Nevertheless, all the professionals who responded to the questionnaire have up-to-date level of awareness of risk assessment methods in life cycle costing.

Practical implications. As a result of growing awareness of whole life costing among corporate occupants and facilities managers in contemporary building projects, precise assessment of cost is a challenging undertaking as it consists of some measure of risk with regards to the running and maintenance costs during the entire life of the buildings. Thus, the existence of considerable improbability and doubt regarding cost and time evidence of an LCC study would have mind blowing implications on final results and consequently have minute bearing on subsequent decisions made by corporate occupiers.

Social implications. Value for money for construction products and its facilities should not be viewed only in terms of costs to design and construction. Rather, it is vital for corporate occupants and society in general to consider other key variables such as operations, maintenance, renovation, replacement, and end of life costs. Originality/value. This paper contributes with new outlooks aimed at assessing the current level of awareness, usage and advocated benefits of risk assessment methods in LCC and adds to the limited empirical studies on risk assessment to corporate occupants and decision makers.
\end{abstract}

Keywords: corporate occupants / life cycle costing / real estate and risk assessment

\section{Introduction}

LCC is a technique which enables comparative cost assessments to be made over a specified period of time, taking into account all relevant economic factors both in terms of initial capital costs and future operational costs

\footnotetext{
* e-mail: o.oduyemi@derby.ac.uk
}

[1]. It also refers to an economic estimation method that evaluates the entire cost of a building to the corporate occupier over its operating life, including initial capital costs, maintenance costs, operating costs and the ultimate disposal of the asset at the end of its life [2].

Kirk and Dell'Isola [3] referred to LCC as a management tool and a decision making tool; a management tool because it can be used to forecast the total costs that will be 
incurred by the corporate occupier during a building's life and a decision making technique because it can be used to pick amongst alternate projects.

Recent guidance for projects procured using the Private Finance Initiative (PFI) or Public Private Partnership (PPP) routes advocates the use of life cycle costing techniques specifically as they provide an assessment of the long-term cost effectiveness of a project.

Similarly, to the corporate occupiers, it can be used as a means of comparing options and their associated costs over a period of time [4] or as a tool for assessing the long terms costs of ownership in existing buildings through stochastic modelling and key performance indicators [5].

In spite of these anticipated benefits, no research has evaluated the use, awareness and benefits of risk assessment methods for lifecycle costing in buildings to corporate occupiers. The relevance of these methods cannot be overemphasised as investing in real estate is long-lasting and as an aftermath consists of some measure of risk with regards to the operating and maintenance costs during the entire life of the structures.

Also, the existence of considerable improbability and doubt regarding cost and time evidence of an LCC study would have mind blowing implications on final results and consequently have minute bearing on subsequent decisions made by corporate occupiers.

Hence, dealing with risk should be fundamental to new approaches of defining real estate particularly in today's extremely unpredictable business environment. This should be the basis of the professionals' method to LCC decision making as the imprecision of prediction has remained a major issue with real estate practitioners and corporate occupiers, therefore, making available information and measuring the risk components would make professionals and occupants more convinced with the information that LCC delivers.

\subsection{The benefits of LCC to corporate occupiers}

It has long been acknowledged that it is unacceptable to appraise the costs of buildings only on the basis of their initial costs. LCC is an estimation method that takes cognisance of all costs that arise all through the life cycle of a development, such as initial investment costs, subsequent operating and maintenance costs, salvage and resale value [6].

The method is mostly applied to enable effective selection among project options by corporate occupiers. It is best carried out during the initial feasibility, practicability and conceptual design where most, if not all, choices are subject to deliberation. According to Norman [7], the several benefits of LCC to corporate occupiers can be identified:

- The commissioning of new buildings to meet a perceived market demand.

- Investment in new capital equipment to achieve specific cost reduction targets.

- Modification of design to improve reliability and performance.

- Decisions on the optimal time to replace ageing facilities.

Akhlaghi [8] also applied LCC analysis and decisionmaking tool to buildings in four different contexts:
- In trading-off exercises between capital and revenue expenditures - often as a useful tool for presenting a case for higher capital expenditure and relaxation of cost limits in favour of better gains in terms of revenue.

- In comparisons between different design solutions that might provide equivalent baseline performance according to conventional criteria.

- In presenting a possibility for investigation into the interrelationship between the performance of a building and its running costs or cost-in-use specification.

Haworth [9] summarises the benefits of LCC to corporate occupiers into four simple ideologies:

- LCC must be used at all decision stages during the design process.

- LCC must comprise of the operation costs within a building.

- The logical procedure must encompass all decisionrelated factors.

Typically, LCC can be applied throughout the following main phases of the life cycle of any facility:

- Preconstruction which involves project investment and planning.

- Design and construction at practical, system and comprehensive component stage.

- During occupation (cost-in-use) and post-construction.

- Disposal (end-of-life).

In sum, LCC is a very adaptable management tool to the corporate occupier as it enables both short-term monitoring and long-term planning of costs to be carried out. LCC tends to change depending on the context it is applied. It may integrate several cost elements, assemble these elements in diverse paths, or even ignore specific cost elements that are considered needless for the specific examination.

LCC allows the corporate occupier to concentrate on important matters, to explore and describe the issues that affect the decision variables and get a deeper understanding of the issues which will affect the final choice. By examining these factors early in the design process, when effective corrective action can be taken, important tradeoffs between capital and running costs can be made.

The LCC approach can also have important benefits during the whole lifetime of the asset as a management tool which can identify short-term running costs of buildings or building components, ascertain ways in which cost savings can be achieved and feedback this information for use in subsequent LCC studies. Similarly, other benefits of LCC to corporate occupiers are discussed in Table 1.

LCC model can be used to forecast the costs of all the life cycle phases for individual scheme and allow occupiers to choose the most viable development on the basis of total performance [10]. The quality of both the design and construction of the building have a substantial effect on the costs. Constructions where the design team exclusively emphasise on plummeting capital costs can result in a structure which is expensive to manage, operate, inhabit and ultimately dispose of.

LCC thus reduces costs and so knowledgeable investment choices might be arrived at dependent on the least likely use of funds. Waak [11] identified situations in which operating and maintenance costs could be lowered by up to 
Table 1. Benefits of LCC to the corporate occupiers.

\begin{tabular}{ll}
\hline LCC identifies whole costs & $\begin{array}{l}\text { LCC methods enable occupiers to recognise the whole costs emanating from buildings } \\
\text { throughout its operational life without looking at only the initial capital costs. }\end{array}$ \\
$\begin{array}{l}\text { LCC acts as a decision } \\
\text { making tool }\end{array}$ & $\begin{array}{l}\text { LCC helps in decision making and leads to functioning and monetary investment } \\
\text { strategies. }\end{array}$ \\
$\begin{array}{l}\text { LCC acts as a management } \\
\text { tool }\end{array}$ & $\begin{array}{l}\text { LCC allows occupiers to select the best resolution and also allows for good control of } \\
\text { the asset during its operation. }\end{array}$ \\
guide & $\begin{array}{l}\text { LCC provides diverse maintenance systems to be adopted, as well as maintenance } \\
\text { cycles and their occurrences and to make repairs/replacement decisions, } \\
\text { improvements, refurbishment decisions and also to agree on the maintenance budget. }\end{array}$ \\
\hline
\end{tabular}

fifty percent, and concurring with Masiello [12], the LCC method makes it conceivable to recognise the utmost important cost generators and hence attains the suitable blend of resources employed. Ferrin and Plank [13] concluded that LCC-based assessment delivers a more long-term assessment for occupiers.

\subsection{The need for risk assessment methods}

Risk is a complex phenomenon that has physical, monetary, cultural and social dimensions [14]. The consequences of risk events go well beyond the direct physical harm to financial or physical assets, people or ecosystems. The effects include the way a society operates and people think [14].

The objectives of risk assessment to corporate occupiers are to increase the probability and impact of positive events, and decrease the probability and impact of events adverse to the buildings [15].

Ideally, all risks should be assessed and accounted for at the outset of the analysis, and given the continually changing nature of risk; the management techniques used should be dynamic in their nature.

Conversations with industry based cost appraisal professionals in the course of conferences and seminars have revealed that the concept of risk is under represented in the industry particularly where decision-making is involved [16,17]. Occasionally when risk is deliberated upon in the information encapsulating activities, it is hardly ever incorporated in the final decision [18].

The lack of risk assessment methods would result in grave restrictions to the use of the LCC methods for corporate occupiers, as cost computations would be inexact, with non-manageable values not being considered.

Applying these procedures and steps would augment the accuracy of cost forecasts, accelerating the integration into the examination of unanticipated happenings all through the life cycle of the building [19]. According to Akintoye and Macleod [20], it is important for minimising losses and increasing profits of the real estate.

Similarly, investments in facilities are long-lived and necessarily involve risks about project life, operating and maintenance costs, and many more factors that affect facilities economics. If there is substantial risk concerning cost and time information, a LCC assessment may have little value for corporate users and decision makers.

Therefore, it is essential to assess the degree of risk associated with the LCC results and to take that additional information into account when making decisions [21,22].
Thus, if the LCC models can introduce some quantitative method of assessing the probabilities of risk, then this kind of barrier can be overcome. The weightiest improbabilities normally take place in the early stages of a project, a time also when investment decisions of the maximum effect are made. However, the risks associated with future cost forecasting carry similar risks.

Likewise, in post occupancy cost analysis, the risks in future capital spending and LCC forecasts need to be quantified. Risk assessment therefore provides useful insights in instances where the probability density function can be precisely defined [23] and reduces the chance of failure and maximise opportunities in the projects.

Merely evaluating risk and subsequently controlling it is not adequate [24]. Formal techniques of risk assessment are required to make certain that some kind of regularity and standardisation is achieved by corporate occupiers.

However, most of these methods are usually difficult, complicated and costly and therefore the application of these methods for numerous projects is exorbitant. The absence of understanding and misgivings as to appropriateness within the built environment professions has also been recognised as explanations for the sluggish take up [25].

Usually, when corporate occupiers are faced with an investment choice under uncertain conditions, their main concern is to avoid projects whose actual economic outcome might be less favourable than what is acceptable, resulting in the risk of missing out on potential investment opportunities. Thus, the objective of LCC risk assessment should be to assist corporate occupiers in evaluating whole life alternatives so that investment success is maximised.

There are three ways of appraising risk as shown in Table 2. This includes the deterministic techniques which evaluates the influence on project results of altering one undefined significant value or an array of values at a time and the occupier ascertaining the level of uncertainty on a biased underpinning, while quantitative approaches are established on the supposition that no lone value can sufficiently characterise the extensive possibility of likely results of an uncertain investment [27].

Instead, a great amount of substitute results needs to be well-thought through and each likelihood should be complemented by a concomitant possibility from a probability distribution, supported by a numerical and arithmetic examination to quantify the level of uncertainty [28]. The 
Table 2. Risk assessment methods in LCC.

\begin{tabular}{|c|c|c|}
\hline Deterministic & Qualitative & Quantitative \\
\hline $\begin{array}{l}\text { Conservative benefit and cost } \\
\text { estimating }\end{array}$ & Risk matrix & $\begin{array}{l}\text { Input estimates using probability } \\
\text { distribution }\end{array}$ \\
\hline Break-even analysis & Risk registers coefficient of variation & Mean-variance criterion \\
\hline Risk-adjusted discount rate & Event trees (qualitative) & Decision tree analysis and Fuzzy sets theory \\
\hline Certainty equivalent technique & $\begin{array}{l}\text { SWOT analysis and likelihood/ } \\
\text { consequence }\end{array}$ & $\begin{array}{l}\text { Simulation (Monte Carlo/Latin hypercube } \\
\text { simulation) }\end{array}$ \\
\hline $\begin{array}{l}\text { Sensitivity analysis and net } \\
\text { present value }\end{array}$ & Risk scoring & Mathematical/analytical technique \\
\hline Variance & Brainstorming sessions & Artificial intelligence \\
\hline
\end{tabular}

Source: Marshall [26].

qualitative approaches vary from the former methods as they utilise qualitative methods to resolve risk and improbability in LCC examination.

\section{Research methodology}

A sample of 120 organisations were electronically emailed questionnaires in the UK with 69 responses thus signifying a response rate of $57.5 \%$ which is in line with the views of Akintoye [29] and Dulami et al. [30]. The adoption of stratified random sampling allowed the researchers more control over the eventual sample to ensure it reflected the makeup of the overall population whilst also minimising the possibility by bias by ensuring every item of the population had an equal probability of being selected [31].

As with previous LCC studies examining industry practice [32-34] the need to ascertain the extent of the use of LCC as an early stage project evaluation tool called for a quantitative research design that made use of a measuring instrument that allowed data to be collected from a large number of practitioners in the field.

Cresswell [35] indicated that the most appropriate data collection tool to use for this element of the study was a questionnaire survey. The design and use of such an instrument enabled the study not only to ascertain the extent of the use of the LCC risk assessment methods in practice but also to uncover the significance of the key advocated benefits of risk assessment in LCC identified from the literature.

Following the piloting of the questionnaire, it was resolved to develop a random sample of survey participants by using Building Magazine's published lists of the top 100 cost consultants, architects, multi-disciplinary and contractors' organisations operating across the UK. As Higham et al. [33] attest, Building's top 100 lists are sufficient in size to allow the whole population to be contacted within the time scale and cost limitations faced by the majority of researchers.

To ensure the validity and reliability of the research findings, the Cronbach's alpha coefficient and the skewness and kurtosis test were used. The Cronbach alpha values of all the variables showed that the values were all statistically significant at 0.084 . The result suggested that the instrument (questionnaire) is highly reliable and that there is an internal consistency of the items included in it.
This is judging from the fact that the reliability figure obtained is substantially higher than $0.7(84.0 \%>70 \%)$ required in statistical analysis [36]. Akintoye [29] also adopted the approach to test the reliability of the Likerttype scale. The larger the value, the better the reliability in each component.

Similarly, the measure of skewness and kurtosis showed that all the data set in the study look the same to the left and right of the centre point and the data has a distinct peak near the mean, decline rather rapidly with heavy tails thus validating the results of the study (see Figs. 1 and 2).

The questionnaire comprised three main sections each exploring different parts of the research question. The first section sought information on the respondent's profile as shown in Tables 3-5.

The second section gauged the current level of awareness and usage of risk assessment methods in LCC and a test of hypothesis to determine if it is important to integrate risk assessment methods into LCC (see Tables 6 and 7). The third section ranked 8 key advocated benefits of risk assessment in LCC identified from the literature (see Tables 8 and 9). The questionnaire responses were assigned numerical codes and the data was analysed using descriptive and inferential statistics (factor analysis) in SPSS 22.

\section{Discussion and results}

Table 3 indicates most respondents 28 were quantity surveyors in the construction industry, 26 were builders, while 9 were facilities managers. Also 4 were estate surveyors while 2 were architects. As the versatility of the respondents is reasonably well-thought-of, opinions and views obtained through the survey can be regarded as important and reliable.

Table 4 indicates most respondents 35 have over 11 years' experience working in the real estate, 20 has industry experience ranging between 6 and 10 years, while 14 have at least 5 years or less. Majority of respondents had reasonable experience in sustainable construction which further shows that respondents are sufficiently experienced enough to provide data which are credible.

Table 5 result shows that 36 of the survey participants were members of the RICS and 22 were members of the CIOB. Similarly, 11 were members of the BIFM. 


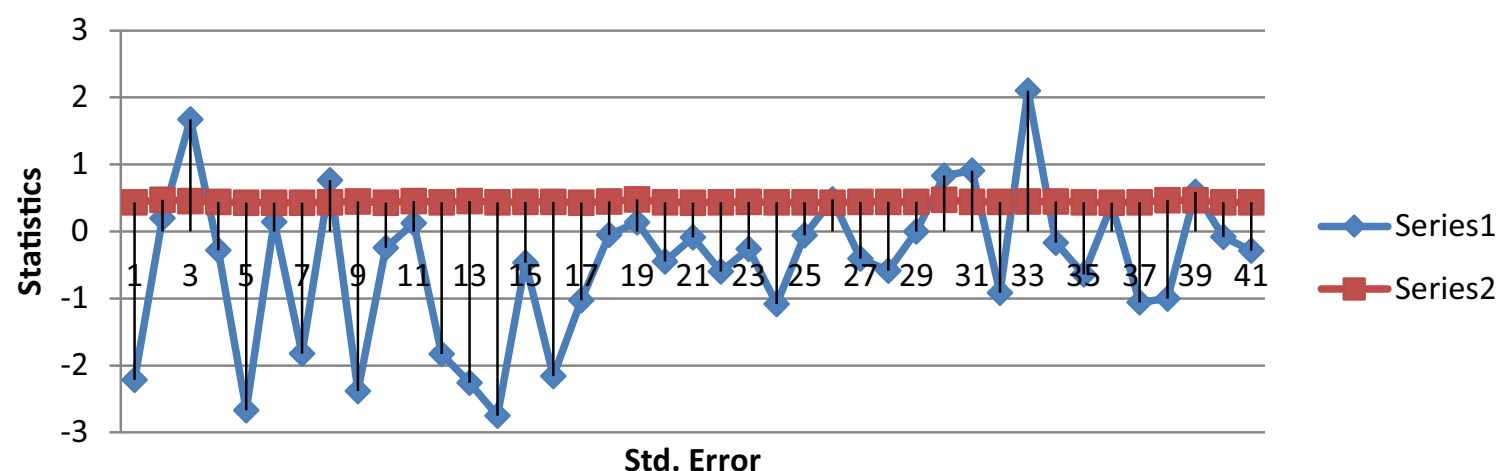

Fig. 1. Measure of skewness.

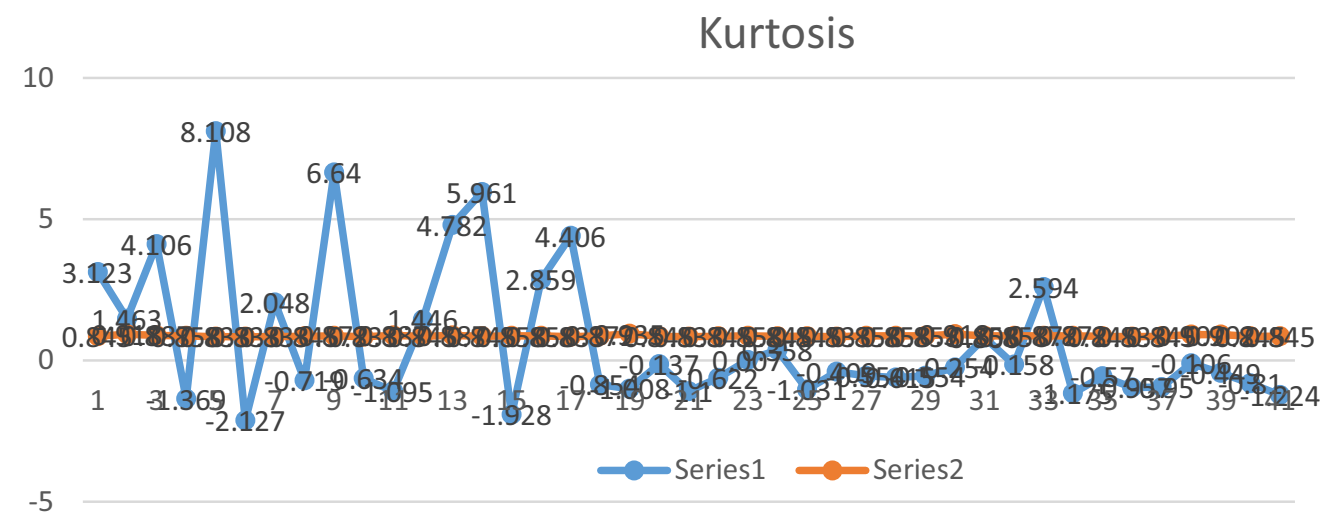

Fig. 2. Measure of kurtosis.

Table 3. Professional background of respondents.

\begin{tabular}{llcccc}
\hline & Participants & Frequency & Percent & Valid percent & Cumulative percent \\
\hline Valid & Quantity surveyors & 28 & 40.6 & 40.6 & 40.6 \\
& Builders & 26 & 37.7 & 37.7 & 78.3 \\
& Architects & 2.9 & 2.9 & 81.2 \\
& Facilities managers & 9 & 13.0 & 13 & 94.2 \\
Estate surveyors & 4 & 5.8 & 5.8 & 100.0 \\
Total & 69 & 100.0 & 100.0 & \\
\hline
\end{tabular}

Table 4. Years of experience of respondents.

\begin{tabular}{|c|c|c|c|c|c|}
\hline & & Frequency & Percent & Valid percent & Cumulative percent \\
\hline \multirow[t]{4}{*}{ Valid } & $0-5$ & 14 & 20.3 & 20.3 & 20.3 \\
\hline & $6-10$ & 20 & 29.0 & 29.0 & 49.3 \\
\hline & 11 and above & 35 & 50.7 & 50.7 & 100 \\
\hline & Total & 69 & 100.0 & 100 & \\
\hline
\end{tabular}

The relevance of professional institutions cannot be over-emphasised as they promote the development of constructive initiatives in real estate risk assessment. Thus, all respondents being members of relevant professional bodies further lend credence to the credibility of the research.

\section{Risk analysis methods need to be integrated into LCC}

The responding construction professionals indicated that there was a need to integrate and incorporate risk assessment methods into LCC as 65 and 4 of respondents 
Table 5. Professional qualifications of respondents.

\begin{tabular}{lllccc}
\hline & Professional institutions & Frequency & Percent & Valid percent & Cumulative percent \\
\hline Valid & RICS & 36 & 52.2 & 52.2 & 52.2 \\
& CIOB & 22 & 31.9 & 31.9 & 84.1 \\
& BIFM & 11 & 15.9 & 15.9 & 100.0 \\
& Total & 69 & 100.0 & 100.0 & \\
\hline
\end{tabular}

Table 6. There is a low level of awareness and usage of risk analysis methods in LCC.

\begin{tabular}{|c|c|c|c|c|c|}
\hline & & Frequency & Percent & Valid percent & Cumulative percent \\
\hline \multirow[t]{3}{*}{ Valid } & Agree & 4 & 5.8 & 5.8 & 5.8 \\
\hline & Strongly agree & 65 & 94.2 & 94.2 & 100.0 \\
\hline & Total & 69 & 100.0 & 100.0 & \\
\hline
\end{tabular}

strongly agreed with this statement (Table 6). Still, risk is either ignored or dealt with in an arbitrary fashion, such as adding a nominal contingency value on to the forecasted cost of the investment decision.

Many now see that such an imprudent way in dealing with risk is unacceptable and that a more methodological approach is required. Nevertheless, the provision for improbability in cost appraisal and forecasting is yet to be addressed.

\section{Test of hypothesis for risk assessment methods}

Hypothesis can be defined as a procedure that allows us to know whether or not possible relationship exist between two or more variables. A statistical hypothesis is an assertion or statement about a probability distribution or about population parameter(s). The Hypothesis tested in this study is to determine whether or not it is important to integrate risk assessment methods into LCC

$H_{0}$ : Proportion of respondents who said it is not important to integrate risk assessment methods into LCC is equal to 0.5

$H_{1}$ : Proportion of respondents who said it is important to integrate risk assessment methods into LCC is less than 0.5

$$
\begin{aligned}
& H_{0}: P=0.5 \\
& H_{1}: P<0.5,
\end{aligned}
$$

$P$ is the proportion of respondents who said it is not important to integrate risk assessment methods into LCC; $P$ is estimated by $\hat{P}$; where $n^{\prime}$ is the number of respondents who said it is important to integrate risk assessment methods into LCC; $n$ is the total number of respondents sample

$$
\begin{aligned}
& \hat{p}=\frac{8}{69}=0.12 \\
& \hat{q}=1-\hat{p}=1-0.12=0.88
\end{aligned}
$$

$$
\begin{aligned}
& \hat{V}(\hat{p})=(1-f) \frac{\hat{p} \hat{q}}{n-1}, f=\frac{n}{N} \\
& \hat{V}(\hat{p})=\left(1-\frac{69}{250}\right) \frac{0.12 \times 0.88}{69-1} \\
& \hat{V}(\hat{p})=0.0009 \\
& Z_{0}=\frac{\left|p-p_{0}\right|}{\sqrt{\hat{V}(\hat{p})}}=\frac{|0.12-0.5|}{\sqrt{0.0009}}=12.67 \\
& Z_{\alpha}=Z_{0.05}=1.64 \quad \text { (Single tailed test). }
\end{aligned}
$$

Hence, $Z_{0}>Z_{\alpha}$. Thus $H_{0}$ is rejected and $H_{1}$ is accepted. That is, it is important to integrate risk assessment methods into LCC.

\section{Benefits of the application of risk assessment methods}

The benefits of the application of risk assessment methods in LCC were ranked using factor analysis. Factor analysis is a multivariate statistical technique for examining the underlying structure or the structure of interrelationships (or correlations) among a large number of variables [37].

This analysis yields a set of factors or underlying dimensions which, when interpreted and understood, describe the data in a parsimonious but more meaningful number of concepts than the original individual variables (Table 7).

This analysis was performed with the assistance of SPSS Statistics v22. Kaiser-Meyer-Olkin (KMO) measure and Bartlett's Test of Sphericity were conducted to examine the sampling adequacy, ensuring that factor analysis was going to be appropriate for the research [38].

From Table 7, the following factors were the most important benefits of the application of risk assessment methods: - Risk assessment augments the accuracy of cost forecasts, accelerating the integration into the examination of unanticipated happenings all through the life cycle of the building. 


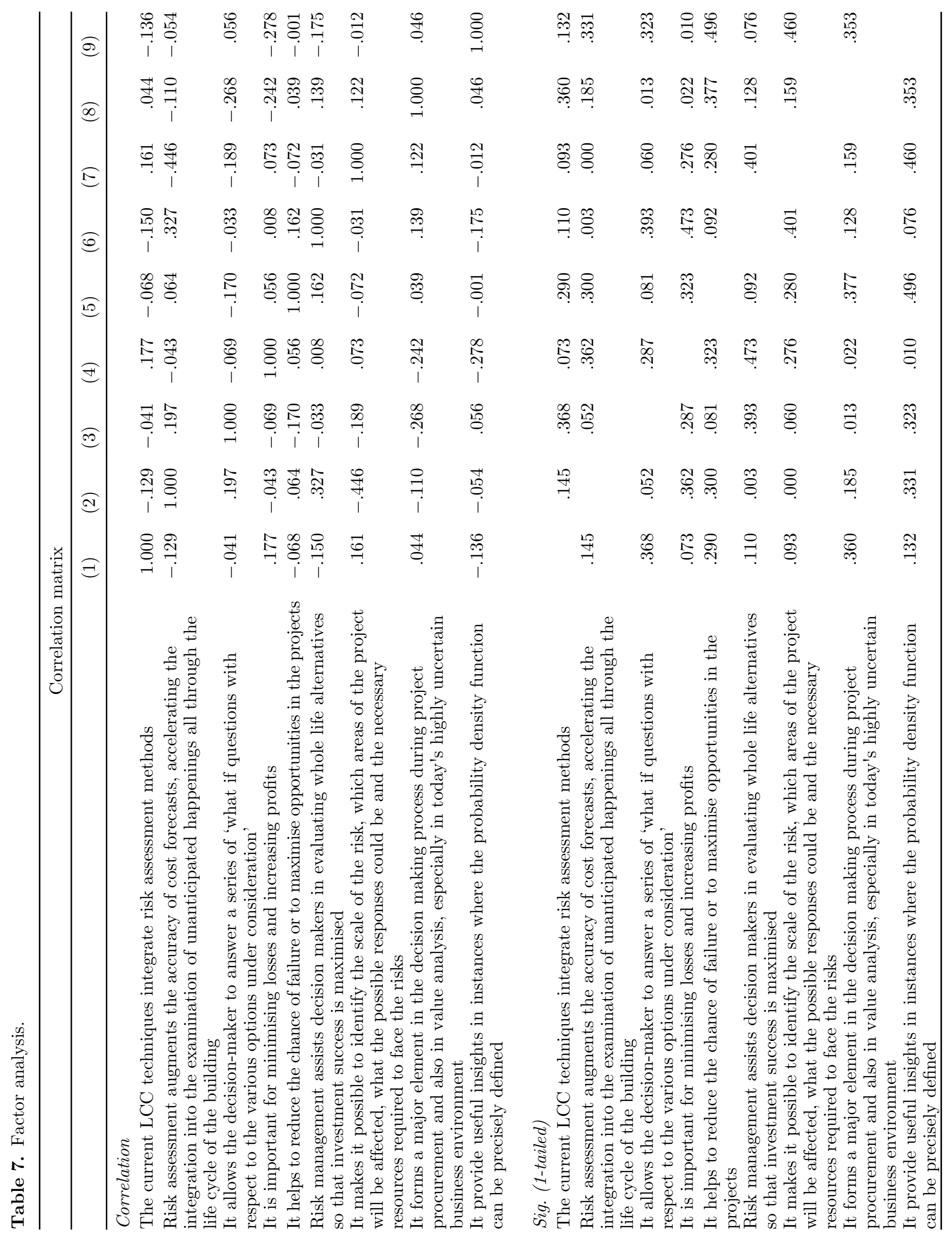


Table 8. Total variance extraction method: principal component analysis.

\begin{tabular}{|c|c|c|c|c|c|c|c|c|c|}
\hline \multirow[t]{2}{*}{ Component } & \multicolumn{3}{|c|}{ Initial Eigenvalues } & \multicolumn{3}{|c|}{$\begin{array}{l}\text { Extraction sums of squared } \\
\text { loadings }\end{array}$} & \multicolumn{3}{|c|}{$\begin{array}{l}\text { Rotation sums of squared } \\
\text { loadings }\end{array}$} \\
\hline & Total & $\begin{array}{l}\% \text { of } \\
\text { Variance }\end{array}$ & Cumulative \% & Total & $\begin{array}{l}\% \text { of } \\
\text { Variance }\end{array}$ & Cumulative \% & Total & $\begin{array}{l}\% \text { of } \\
\text { Variance }\end{array}$ & Cumulative $\%$ \\
\hline 1 & 1.799 & 19.992 & 19.992 & 1.799 & 19.992 & 19.992 & 1.424 & 15.824 & 15.824 \\
\hline 2 & 1.463 & 16.253 & 36.245 & 1.463 & 16.253 & 36.245 & 1.384 & 15.376 & 31.200 \\
\hline 3 & 1.443 & 16.033 & 52.278 & 1.443 & 16.033 & 52.278 & 1.267 & 14.073 & 45.273 \\
\hline 4 & 1.009 & 11.209 & 63.487 & 1.009 & 11.209 & 63.487 & 1.226 & 13.625 & 58.898 \\
\hline 5 & .881 & 9.784 & 73.271 & .881 & 9.784 & 73.271 & 1.036 & 11.510 & 70.408 \\
\hline 6 & .758 & 8.419 & 81.690 & .758 & 8.419 & 81.690 & 1.015 & 11.282 & 81.690 \\
\hline 7 & .660 & 7.329 & 89.018 & & & & & & \\
\hline 8 & .559 & 6.206 & 95.224 & & & & & & \\
\hline 9 & .430 & 4.776 & 100.000 & & & & & & \\
\hline
\end{tabular}

- It allows the decision-maker to answer a series of 'what if questions with respect to the various options under consideration.

- It is important for minimising losses and increasing profits.

- it helps to reduce the chance of failure or to maximise opportunities in the projects).

The above factors resulted with eigenvalues greater than 1, capturing $63.487 \%$ of total variance as shown in Table 8.

The value of KMO is 0.524 , which is above Kaiser's [39] specification of 0.5 . Therefore, the results shown in Table 9 proved that all the factors presented an adequate reliability. The four factors earlier mentioned however stood out as crucial and pertinent benefits of the application of risk assessment methods. The factor scores were generated by using the Bartlett method which calculates for each response, the "weighted sum" of their standardized value for every variable multiplied by the corresponding factor loading of the variable.

\section{Conclusion and recommendations}

As discussed above, there is a low awareness and usage of risk assessment methods in LCC. It is also expedient to integrate these methods in LCC calculations in order to improve the precision of forecasts for corporate occupiers. Failure to do this would result in not reaping the benefits of the LCC applications, as cost computations would be inexact. Applying these procedures and steps would augment the accuracy of cost forecasts, accelerating the integration into the examination of unanticipated happenings all through the life cycle of the building.

Dealing with risk in LCC should be the cornerstone of the corporate occupier's approach to LCC decision making as the risk and uncertainty of forecasting has always been a key problem with practitioners, so by providing information and quantifying the risk elements, corporate occupiers should be more confident in the information that LCC can provide.
Table 9. KMO and Bartlett's test.

Kaiser-Meyer-Olkin measure of sampling adequacy $\quad .524$

Bartlett's tet of sphericity Approx. Chi-square 58.038

Df 36

Sig. $\quad .011$

In response, a number of remedial actions have been suggested such as the development of a standardised LCC approach integrating risk assessment methods. Similarly, professional organisations like the RICS could encourage increased LCC education for their members. This research has drawn attention to the importance of dealing with risk as risk assessment is one of the important issues facing building assets corporate occupiers today. As spending on building assets rises, corporate occupiers become increasingly worried about LCC optimisation throughout the life span of facilities; consequently, they become highly vulnerable to the risk of operational costs.

Thus, the objective of LCC risk assessment should be to assist corporate occupiers in evaluating whole life alternatives so that investment success is maximised. The key to successfully harnessing the anticipated benefits is to build a LCC framework that requires from the occupiers nothing more than they presently can provide.

This can be achieved through the use of a variety of techniques ranging from simple deterministic approaches to uncertainty assessment (e.g. sensitivity and break even analysis methods which are easy to use and understand and require no additional methods of computation beyond the ones used in LCC analysis), to very sophisticated methods based on probabilities, artificial intelligence (AI) and a hybrid of both techniques.

This paper has gauged the current level of awareness, usage and given an overview of the advocated benefits of risk assessment methods in LCC with suggestions on how its implementation can be improved. This has led to the identification of the most relevant benefits facilitating its implementation. 
This would effectively allow researchers to be more aware about the benefits expediting the frequent application of LCC risk assessment methods. It is hoped that as a consequence, the industry will make constructive strides towards application of these measures as a mechanism for considering the cradle to grave implications of their work.

\section{References}

1. ISO, ISO 15686 - Part 1: Service life planning (International Organisation for Standardisation, Geneva, Switzerland, 2000)

2. R. Flanagan, G. Norman, J. Meadows, G. Robinson, Life cycle costing: theory and practice (Basil Blackwell Scientific Publishing, Oxford, 1989)

3. S.J. Kirk, A.J. Dell'Isola, Life-cycle costing for design professionals (McGraw-Hill, New York, 1995)

4. R.M. Cuéllar-Franca, A. Azapagic, Life cycle cost analysis of the UK housing stock, Int. J. Life Cycle Assess. 19, 174-193 (2014)

5. R.J. Kirkham, A.H. Boussabaine, J.P. Jones, Modelling energy costs for whole life costing in the NHS Estate, in Proceedings of the 2000 Construction and Building Research Conference of the Royal Institution of Chartered Surveyors (COBRA), University of Greenwich (2000)

6. M. Kishk, A. Al-Hajj, An integrated framework for life cycle costing in buildings, in Proceedings of the COBRA 1999 RICS Construction and Building Research Conference, September 1-2, 1999 (Economics 23, 1999), Vol. 2, 91-101

7. G. Norman, Life cycle costing, Property Manag. 8, 344-356 (1990)

8. F. Akhlaghi, Life cycle costing - a tool for decision making, Facilities 5, 4-10 (1987)

9. D. Haworth, The principles of life cycle costing, Industrial. Forum 6 (1975)

10. M. Arja, G. Sauce, B. Souyri, External uncertainty factors and LCC: a case study, Buil. Res. Inf. 37, 325-334 (2009)

11. O. Waak, Cut maintenance and logistics support cost with $50 \%$, a fantasy or a feasibility (2004), http://www.systecon. se

12. G.L. Masiello, Reliability, the life cycle driver: an examination of reliability management, culture and practices, Master of Science Thesis, US Naval Postgraduate School, Monterey, CA, 2002

13. D. Ferrin, E. Plank, Total cost of ownership models: an exploratory study, J. Supply Chain Manag. 38, 18-29 (2002)

14. M. Loosemore, J. Raftery, C. Reilly, D. Higgon, Risk management in projects (Taylor \& Francis, London, 2006), second ed.

15. G. Fernández-Sánchez, F. Rodríguez-López, A methodology to identify sustainability indicators in construction project management - application to infrastructure projects in Spain, Ecol. Ind. 10, 1193-1201 (2010)

16. A. Langridge, Uncertainty, in SCAF Workshop on Defence Indecision, Bristol, UK (2010)
17. F.E. Huffman, Corporate real estate risk management and assessment, J. Corp. Real Estate 5, 31-41 (2003)

18. M. Kishk, A. Al-Hajj, R. Pollock, G. Aouad, N. Bakis, M. Sun, Whole life costing in construction - a state of the art review, RICS Found. Res. Pap. 4, 1-39 (2003)

19. A. Boussabaine, Cost planning of PFI and PPP building projects (Routledge, 2013)

20. A.S. Akintoye, M.J. Macleod, Risk analysis and management in construction, Int. J. Project Manag. 15, 31-38 (1997)

21. A. Boussabaine, R. Kirkham, Whole life-cycle costing: risk and risk responses (Blackwell, Oxford, 2008)

22. J.E. Mason, J.Z. Pearlson, R.R. Puga, S.C. Houldin, Making environmentally challenged deals work: tools to manage risk and unlock value in contaminated real estate assets, J. Corp. Real Estate 5, 243-25 (2003)

23. B. Dhillon, Life cycle costing: techniques, models and applications (Routledge, 2013)

24. S.C. Ward, C.B. Chapman, A risk management perspective on the project life cycle, Int. J. Project Manag. 13, 145-150 (1995)

25. P.X. Zou, G. Zhang, J.Y. Wang, Identifying key risks in construction projects: life cycle and stakeholder perspectives, in Pacific Rim Real Estate Society Conference (2006)

26. H.E. Marshall, Technology management handbook (CRC Press, NY, 1999), Chapter 8.12

27. W. Baker, H. Reid, Identifying and managing risk (Pearson Education, Frenchs Forest, N.S.W., 2005)

28. A. Hinge, D. Winston, B. Stigge, B. Happold, Moving toward transparency and disclosure in the energy performance of green buildings (American Council for an Energy Efficient Economy, Washington, DC, 2006)

29. A. Akintoye, Analysis of factors influencing project cost estimating practice, Constr. Manag. Econ. 18, 77-89 (2000)

30. M.F. Dulami, F.Y.Y. Ling, A. Bajracharya, Organisational motivation and inter-organisational interaction in construction innovation in Singapore, Constr. Manag. Econ. 21, 307-318 (2003)

31. R. Sapsford, Survey research (Sage Publications, London, 2007), second ed.

32. O. Oduyemi, M.I. Okoroh, A. Dean, Economic performance measures for life cycle costing in buildings, in RICS COBRA, Sydney, Australia, 8-10 July, 2015 (2015)

33. A. Higham, F. Chris, J. Howard, Life cycle costing: evaluating its use in UK practice, Struct. Surv. 33, 73-87 (2015)

34. E. Sterner, Life-cycle costing and its use in the Swedish building sector, Build. Res. Inf. 28, 387-393 (2000)

35. J. Cresswell, Research design: qualitative and quantitative approach (Sage, London, 2003)

36. A. Field, Discovering statistics using SPSS (Sage Publications, 2009)

37. J.F. Hair, R.E. Anderson, R.L. Tatham, W.C. Black, Multivariate data analysis (Prentice Hall, Upper Saddle River, NJ, 1998)

38. A. Fields, Discovering statistics using SPSS for Windows (Sage Publications, London, 2000)

39. H.F. Kaiser, An index of factorial simplicity, Psychometrika 39, 31-36 (1974)

Cite this article as: O. Oduyemi, M. Okoroh and O.S. Fajana: Risk assessment methods for life cycle costing in buildings. Sust. Build. 1, 3 (2016). 